community studies $(25-30 \%)$. This may be related to age or reluctance to disclose. USEs should be researched further in this population, to develop intervention strategies.

Disclosure of interest statement Nil.

\section{P03.17 THE VICTORIAN ABORIGINAL HEALTH SERVICE (VAHS) CONDUCTED A YOUNG PEOPLE'S SEXUAL HEALTH AND SEXUALLY TRANSMISSIBLE INFECTIONS AND BLOOD BORNE VIRUS (STI/BBV) KNOWLEDGE, ATTITUDES AND BEHAVIOUR SURVEY IN NOVEMBER 2014}

Maurice Shipp, Sandra Gregson*. Research Excellence in Aboriginal Community Controlled Health (REACCH) Project, Victorian Aboriginal Health Service, Fitzroy, Victoria, Australia

\subsection{6/sextrans-2015-052270.245}

The survey was an outcome identified within the Research Excellence in Aboriginal Community Controlled Health (REACCH) collaboration between the Kirby Institute, University of NSW, the National Aboriginal Community Controlled Health Organisation and five Aboriginal Community Controlled Health Services (ACCHS): Younger staffs employed in the service were involved in the development and delivery of the project as a research capacity building component of the project.

Methodology A cross sectional survey, using a self-completed questionnaire was developed as part of the overall REACCH Project. The survey has been coordinated in a number of REACCH stakeholder ACCHOs, it was then reorientated toward the Victorian Aboriginal community by VAHS Staff in collaboration with members of the REACCH Study team.

Participants were Aboriginal and Torres Strait Islander aged 16-29 years. Potential participants were approached as they attended VAHS. The young peoples' survey included fifty seven questions that were sectionalised on Demographic characteristics, General Health and Wellbeing, Knowledge of STIs/BBVs, Behaviour and Risks, and Health Service Utilisation.

Results 102 Young People participated in the survey. Overall there was good knowledge of STI/BBV with some gaps clearly identified. Eighty Seven young people identified as being of Aboriginal heritage, with two people being Torres Strait Islander, five people identified as both Aboriginal and Torres Strait Islander and four participants identified as non-Indigenous.

Conclusion Overall there was excellent knowledge of STI/BBV and contraception and reported strategies for accessing health care and information. Specific gaps were identified that can inform future Health Promotion messages and clinical care. VAHS was considered to be an appropriate health service for a majority of these young people to discuss sexual and reproductive health care.

\section{P03.18 KNOWLEDGE REGARDING HIVIAIDS AND VIEWS ON HIV TESTING BEFORE MARRYING MIGRANT WORKERS AMONG RURAL HIGHER SECONDARY SCHOOL STUDENTS IN BANGLADESH}

ME Hoque*. University of KwaZulu-Natal (Westville Campus), South Africa

\subsection{6/sextrans-2015-052270.246}

Introduction The social context of Bangladesh does not permit adolescents to discuss reproductive health topics as well as sexually transmitted diseases like HIV/AIDS openly with their parents, teachers, or other senior members of the community.
Methods This was a cross-sectional study to investigate knowledge regarding HIV/AIDS and views on HIV testing before marrying migrant workers among rural grade 11 and 12 students in Bangladesh.

Results A total of 92 students completed anonymous, self-administered questionnaire. The average age of the students was 16.8 \pm 0.9 years. All the students had heard about AIDS before they complete the questionnaire. Media (75\%) was the main source of information. Overall, students had average knowledge regarding selected aspects of HIV/AIDS. A high $(>73 \%)$ proportion of students were conversant with the major modes of spread of HIV. Many misconceptions were still noted relating to HIV/ AIDS, $40 \%$ believing that healthy looking person cannot be infected with HIV, $27 \%$ and $25 \%$ believing that coughing and sneezing and mosquito bites spread AIDS respectively. Majority $(75 \%)$ of the students indicated that they would not ask to do HIV test before marriage and amongst them more than a quarter reasoned as it might lead to break the marriage/marriage might not take place.

Conclusion The knowledge level seems to be low and misconceptions about the routes of transmission were common. It is recommended that strategies for adolescents AIDS risk reduction be developed in Bangladeshi high schools.

Disclosure of interest statement There is nothing to declare.

\section{P03.19 SCREENING FOR SEXUALLY TRANSMITTED INFECTIONS IN ADOLESCENT GIRLS AND YOUNG WOMEN IN MOMBASA, KENYA}

${ }^{1} \mathrm{~L}$ Masese ${ }^{*},{ }^{2} \mathrm{G}$ Wanje, ${ }^{2} \mathrm{E}$ Avuvika, ${ }^{2} \mathrm{E}$ Kabare, ${ }^{3} \mathrm{~V}$ Budambula, ${ }^{3} \mathrm{~F}$ Mutuku, ${ }^{4} \mathrm{G}$ Omoni, ${ }^{5} \mathrm{~A}$ Baghazal, ${ }^{6,7,8}$ BA Richardson, ${ }^{1,9,6,2}$ RS McClelland. 'Department of Medicine, University of Washington, Seattle, WA, USA; ${ }^{2}$ University of Nairobi Institute of Tropical \& Infectious Disease (UNITID), Nairobi, Kenya; ${ }^{3}$ Department of Environmental Health, Technical University of Mombasa, Mombasa, Kenya; ${ }^{4}$ School of Nursing Sciences, University of Nairobi, Nairobi, Kenya; ${ }^{5}$ Mombasa County Department of Health, Mombasa, Kenya; ${ }^{6}$ Department of Global Health, University of Washington, Seattle, WA, USA; ${ }^{7}$ Department of Biostatistics, University of Washington, Seattle, WA, USA; ${ }^{8}$ Vaccine and Infectious Disease Division, Fred Hutchinson Cancer Research Center, Seattle, WA, USA; ${ }^{9}$ Department of Epidemiology, University of Washington, Seattle, WA, USA

\subsection{6/sextrans-2015-052270.247}

Introduction As adolescents and young women become sexually active, they are at risk of adverse reproductive health outcomes including sexually transmitted infections (STIs). We assessed feasibility and acceptability of STI screening among 15-24 year-old women in Mombasa County, Kenya.

Methods Participants were recruited from three high schools and one university. Study staff conducted informational sessions. Students interested in participating were given informed assent/consent forms to take home, and asked to visit our clinic for STI screening. During clinic visits, participants completed a selfadministered questionnaire and provided a urine specimen to test for Neisseria gonorrhoeae, Chlamydia trachomatis, and Trichomonas vaginalis using the Hologic Aptima Detection System. Results Between August 2014 and March 2015, 463 high school and 165 university students collected assent/consent forms. Of these, 293 (63\%) from high schools versus 158 (95\%) from university attended clinic for STI screening $(\mathrm{p}<0.001)$. Of the 153 $(34 \%)$ who reported any history of insertive vaginal sex, 76 $(50 \%)$ reported condom use, and $31(20 \%)$ reported hormonal contraceptive use at the last sex act. Twenty-six (5.8\%) students had STIs (7 [1.6\%] with N. gonorrhoeae, 16 [3.6\%] with C. trachomatis and 3 [0.7\%] with T. vaginalis). Older age (OR 1.28; 